\title{
Effects of Cyriax Manual Therapy versus Mulligan Technique on Grip Strength and Functional Outcomes in Patients with Lateral Epicondylitis
}

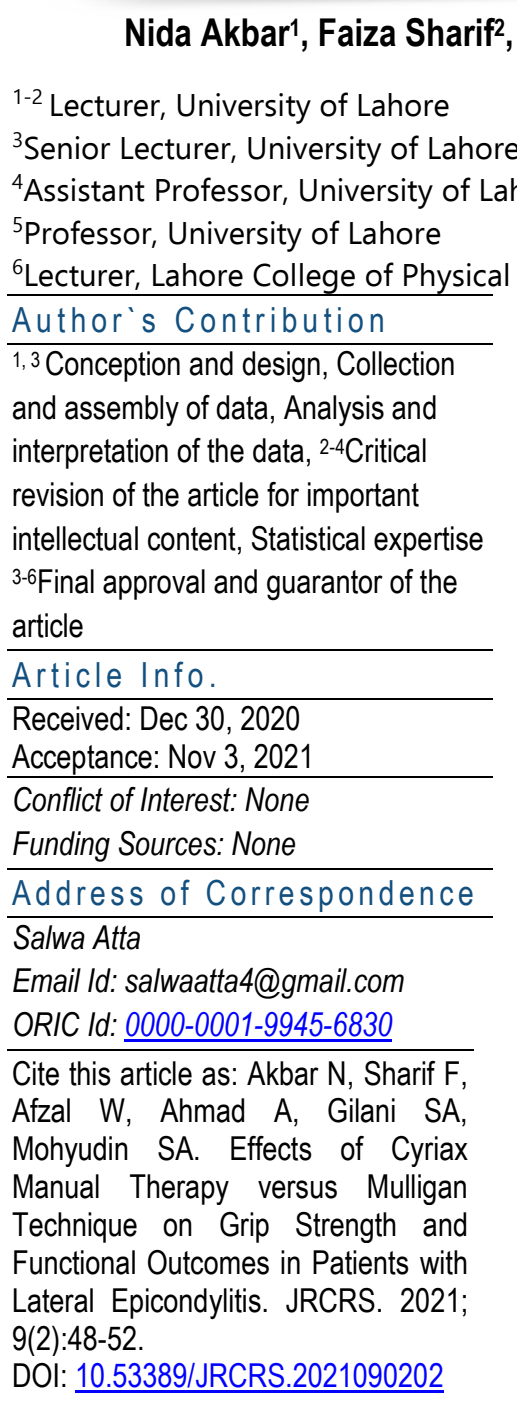

${ }^{1-2}$ Lecturer, University of Lahore

${ }^{3}$ Senior Lecturer, University of Lahore

${ }^{4}$ Assistant Professor, University of Lahore

${ }^{5}$ Professor, University of Lahore

${ }^{6}$ Lecturer, Lahore College of Physical Therapy

Author's Contribution

${ }^{1,3}$ Conception and design, Collection

and assembly of data, Analysis and

interpretation of the data, ${ }^{2-4} \mathrm{Critical}$

revision of the article for importan

intellectual content, Statistical expertise

3-6Final approval and guarantor of the

article

Article Info

Received: Dec 30, 2020

Acceptance: Nov 3, 2021

Conflict of Interest: None

Funding Sources: None

Address of Correspondence

Email Id: salwaatta4@gmail.com

Cite this article as: Akbar $\mathrm{N}$, Sharif $\mathrm{F}$, Afzal W, Ahmad A, Gilani SA Mohyudin SA. Effects of Cyriax Manual Therapy versus Mulligan Strength and Lateral Epicondylitis. JRCRS. 2021; DOI: 10.53389/JRCRS.2021090202 up.

A B S T R A C T
Objective: To examine the effects of Cyriax manual therapy and Mulligan technique on Grip
strength and functional outcomes among the patients of lateral epicondylitis.
Methodology: This was a randomized control trial conducted in a duration of eighteen months. 66 diagnosed patients from Gosha E Shifa Hospital were recruited for the study and were randomized through computer number generator into group $A$ and $B$. The two primary outcomes were measured i.e. Dynamometer for grip strength and Patient-Rated Tennis Elbow Evaluation Questionnaire for functional outcomes. Research assessor assessed patients before treatment i.e. t1, between treatment i.e. t2 and after treatment i.e. t 3 . The response rate of overall study was $91.33 \%$ thus complying with rule of $85 \%$ follow

Results: The patients who were in group A had mean age of $36.12 \pm 7.56$ years and 33.91 \pm 3.4 years patients in group B. Grip strength measured by hand grip dynamometer was found to be $32.7 \pm 1.41$ and $33.3 \pm 1.34$ at Pre-treatment level ( $p=0.07$ i.e. non-significant), $42.1 \pm 1.30$ and $38.6 \pm 2.82$ at mid treatment level ( $p=0.00$ i.e. significant) and $53.5 \pm$ $2.13 \& 42.3 \pm 1.97$ at post treatment level $(p=0.00$ i.e. significant). Functional outcomes measured by Patient-Rated Tennis Elbow Evaluation Questionnaire was found to be 78.06 \pm 2.76 and $76.93 \pm 1.71$ at Pre-treatment level ( $p=0.053$ |i.e. non-significant), $60.61 \pm 3.78$ and $38.06 \pm 5.73$ at mid treatment level ( $p=0.00$ i.e. significant), $26.86 \pm 2.43$ and $7.66 \pm$ 1.64 at post treatment level ( $p=0.00$ i.e. significant).

Conclusion: The present study concluded that Grip strength was improved by Cyriax manual therapy better than mulligan technique, while Functional status was improved by Mulligan techniques better than Cyriax manual therapy.

Keywords: Cyriax Manual Therapy, Lateral Epicondylitis, Mulligan Technique, PatientRated Tennis Elbow Evaluation

\section{Introduction}

Amongst many of the treatment options possible for tennis elbow, some conservative techniques include acupuncture, electrical stimulations (TENS/EMS), ultrasound radiations, stretching and strengthening exercises, orthotics \& prosthetics, laser therapy and extra corporeal shockwave therapy. ${ }^{1} \mathrm{No}$ ideal treatment has been emerged for Lateral Epicondylitis. Many clinicians advocate a conservative approach as the treatment of choice for Lateral Epicondylitis. Physiotherapy is known to be a conservative treatment which is recommended for Lateral Epicondylitis patients. A wide variety of physical therapy services have already been in use for Lateral Epicondylitis. These techniques of physical therapy have different mechanisms of action but they have a combined effects on reduction of pain and improvement of function. ${ }^{2}$ There is a strong evidence to suggest discordance between clinical severity and tendon pathology in patients with tendinopathy. ${ }^{3}$

Some histological features of lateral epicondylitis are similar to those of tendinopathies and include accumulation of 
ground substance, increased cellularity, neurovascular growth and collagen disorganization. 4,5 One of the challenges in managing Lateral epicondylitis is the wide range of prognosis among individuals with the condition. ${ }^{1-3,6}$ Many non-operative treatment options are now available for lateral epicondylitis but no directions of using and implementing them are provided yet. The fact is that a critical appraisal of clinical trials, systematic reviews as well as meta-analysis which studied these treatment modalities revealed that no single treatment achieves reliable and outstanding results. ${ }^{4}$ Few studies from the literature show that eccentric-concentric loading exercises reduce pain and manage tendon pain..$^{5}$ There are many studies that show that manual therapy and conventional physiotherapy both reduce pain and dysfunctions associated with chronic lateral epicondylitis. It is evident from the existing literature that manual therapy based on Mulligan principle improved pain and dysfunction greatly as compared to conventional Physiotherapy and that Mobilization with Movement claim to provide relief and reduction in pain and improve function. 6,7 Many reviews have looked into the effectiveness of manual therapy and physiotherapy in the management of Lateral epicondylitis, but none has specifically examined the role of Mobilization with movement in Lateral Epicondylitis. These are known to improve pain, physical fitness, inflammation and hand grip. ${ }^{7}$ Reoccurrence of inflammation can be prevented by modifications in daily activities, using assistive devices and by altering techniques and equipments. ${ }^{8}$ Cyriax manual therapy is the development of a specific type of connective tissue massage which is performed at the exact site and location of the lesion with depth of friction massage which is tolerable by the patient. The effect of site numbness in response to the deep transverse friction is because of the pain provoking metabolites. $^{9}$

The study shall provide a better evidence to determine and compare the effectiveness of Cyriax approach and mulligan approach in improving functional status and hand grip strength in sub-acute lateral epicondylitis.

\section{Methodology}

This was a double blinded and Randomized Clinical Trial conducted in a duration of eighteen months. This trial was registered in WHO Registry of IRCT having reference number IRCT20200608047698N1. 66 subjects were included in the study after they were found eligible and set according to the inclusion criteria of the study. Total eighty six patients of both genders were assessed, with the informed consent, according to eligibility criteria by the assessor who was blinded to the group allocation of the patients then sixty six patients were recruited randomly according to inclusion criteria. The inclusion criteria included both males and females of $20-50$ years who were earlier diagnosed with Lateral epicondylitis by an orthopedic physician. Patients were excluded if they had any surgery prior to the diagnosis or treatment by physical therapist, any history of trauma to the elbow, any steroidal injections injected into the shoulder, hypersensitivity of skin, systematic diseases like Rheumatoid Arthritis or SLE and any infection of skin at treatment site i.e. elbow.

In randomization process, the participants were randomly allocated into either group A i.e. Cyriax group or group B i.e. Mulligan group. The participants were assigned the group through Random number generator. Patients were blind to the groups they were allocated and assessor was also blind to the assigned intervention. Sample Size Determination: Sample size of 56 was calculated by using G-power Analysis Software, Version (3.1.9.2) with 0.80 power of study, with 0.5 margin of error and $95 \%$ confidence interval. To manage anticipated dropouts total recruited participants were 66 before the completion of the study and in each group, thirty three patients were allocated. Outcome measures: Primary Outcome Measure: Grip strength was the primary outcome measure of this study. Dynamometer was used to evaluate and record the grip strength of affected hand. The mean grip strength for the dominant hand of men $25-29$ years of age is $49.7 \mathrm{~kg}$ and 18.7 $\mathrm{kg}$ for the non-dominant hand of women 75 to 79 years of age. Secondary Outcome Measure: Patient Rated Tennis Elbow Evaluation is used to assess pain and disability in patients of tennis elbow or lateral epicondylitis. It consists of 5 items that assess pain and 10 to assess disability. Lower scores show no disability or minimum disability whereas higher scores of PRTEE show higher disability.

The measurements were taken before the application of treatment which was baseline measurements by the assessor who was blind to the group of patients being allotted. After four weeks, same assessor took second measurements known as between treatment measurements and post treatment measurements were taken after eight weeks. Routine physical therapy/ conventional physical therapy was administered firstly in patients of both groups.

Intervention: Cyriax Manual Therapy: Patients of group A were provided 12 sessions in 4 weeks with 3 sessions in each week on alternate days. TENS, basic strengthening or isometric exercises of extensor carpi longus and deep friction massage was applied on patients of both groups. Mill's manipulation at elbow was also applied in patients of group A. ${ }^{3}$ Mulligan Manual Therapy: Patients of group B were provided the same number of physiotherapy sessions as of Group A patients. Basic treatment was the same as of group B. 10 
minute Mulligan technique was pplied on elbow in supine position, shoulder positioned as internal rotation, forearm pronation and elbow extension with 10 repetitions for 6 seconds with 15 seconds duration of rest in between. ${ }^{5}$

Statistical Analysis: The data was analyzed using Statistical Package for the Social Sciences (SPSS) for windows software, version 25. Statistical significance was set at $P=0.05$ and it was performed on the basis of intention to treat analysis. For Descriptive Statistics Frequency tables and bar charts were used. Parametric test was used to compare two population at different various intervals.

\section{Results}

86 patients were screened for eligibility criteria. 20 patients did not give consent to be included in the study and were thus excluded. 66 patients agreed to participate and were thus randomized to group A: Cyriax manual therapy $(n=33)$ (age, $36.12 \pm 7.56$ years) group B: Mulligan group $(n=33)$ (age, $33.91 \pm 3.4$ years). There was no significant difference among groups for both demographic (age) and measured variables (Grip strength, Patient rated Tennis Elbow evaluation) at baseline. (Table I)

\begin{tabular}{|c|c|c|c|c|}
\hline \multicolumn{5}{|c|}{ Table I: Characteristics of patients } \\
\hline Variable & \multicolumn{2}{|l|}{ Group A } & \multicolumn{2}{|c|}{ Group B } \\
\hline Age Of & Mean & 36.12 & Mean & 33.91 \\
\hline Participants & Std. Deviation & 7.56 & Std. Deviation & 3.4 \\
\hline Gender of & Males & 21 & Males & 14 \\
\hline \multirow[t]{2}{*}{ participants } & Females & 12 & Females & 19 \\
\hline & Mechanic & 04 & Mechanic & 07 \\
\hline Occupation & Driver & 02 & Driver & 03 \\
\hline of & Banker & 07 & Banker & 03 \\
\hline \multirow[t]{3}{*}{ participants } & Housewife & 08 & Housewife & 06 \\
\hline & Tailor & 05 & Tailor & 08 \\
\hline & Chef & 07 & Chef & 06 \\
\hline Body mass & Underweight & 0 & Underweight & 01 \\
\hline \multirow[t]{2}{*}{ index } & Normal & 29 & Normal & 23 \\
\hline & Obese & 04 & Obese & 09 \\
\hline Duration of & $5-10$ days & & 5-10days & 03 \\
\hline \multirow[t]{4}{*}{ Symptoms } & $11-15$ days & & 11-15days & 14 \\
\hline & $16-20$ days & & 16-20days & 04 \\
\hline & $21-25$ days & & 21-25days & 11 \\
\hline & 26-30 days & & 26-30days & 01 \\
\hline Co & Hypertension & 11 & Hypertension & 08 \\
\hline Morbidities & Diabetes Mellitus & 02 & Diabetes Mell & litus 09 \\
\hline of & Cardiac Problems & s 01 & Cardiac Proble & ems 05 \\
\hline \multirow[t]{2}{*}{ participants } & Others & 11 & Others & 08 \\
\hline & None & 08 & None & 03 \\
\hline Elbow & Right Elbow & 20 & Right Elbow & 14 \\
\hline Effected & Left Elbow & 13 & Left Elbow & 19 \\
\hline
\end{tabular}

Multivariate tests for outcome measures indicate a statistically significant group-by-time interaction ( $F=4.46$, $\mathrm{p}=.00$ ). The univariate group-by-interaction was statistically significant group-by-time interaction. ( $F=2.23, P=.11)$. Post hoc tests revealed that at Mid treatment level and at post treatment level the mean values of the grip strength were significantly reduced in patients who received both interventions $(P=.001)$. Mean values of grip strength were significantly reduced at post treatment level in Group A and B who received Cyriax Manual Therapy $(P=.001)$ and Mulligan Manual Therapy i.e. (.022) whereas functional outcomes were significantly improved in group B (0.00) compared to Group A ( $P=0.02)$ (Table II). A paired $t$ test revealed that there was a significant increase in mean values of MDF in all groups $(p<.01)$.

Independent Sample T test comparison of baseline characteristics of both groups revealed that groups were similar and comparable. There was no noteworthy distinction between the groups for Age $(p=1.30)$, Pre-Treatment Grip Strength $(p=0.07)$ and Pre-Treatment PRTEE score $(p=0.65)$. Results of the independent $t$ test between the group analysis showed that Cyriax group and Mulligan group varied statistically significantly in expressions of Post-treatment grip strength $42.1 \pm 1.30$ and $38.6 \pm 2.82$ respectively ( $p$-value $=0.00$ ). Grip strength results at post- treatment level for both groups were $53.5 \pm 2.13$ and 42.3 \pm 1.97 respectively with a $p$-value of 0.00 i.e. significant. These results depict that Cyriax group had better grip strength as compared to those treated with Mulligan Mobilization with Movement. Results of the independent $t$ test between the group analysis showed that Cyriax group and Mulligan Group varied statistically significantly in expressions of Mid -treatment functional ability $60.61 \pm 3.78$ and $38.06 \pm 5.73$ respectively ( $p$ value $=0.00$ ). Patient Rated Tennis Elbow Evaluation results at $8^{\text {th }}$ week Post-Treatment for both groups were $26.86 \pm 2.43$ and $7.66 \pm 1.64$ respectively with a p-value of 0.00 i.e. significant. These results depict that Mulligan group had better functional outcomes as compared to those treated with Cyriax Mobilization.

\section{Discussion}

The results of this study concluded that Mulligan approach was found to be more effective in improving functional status of lateral epicondylitis. The mechanism by which Mulligan MWM concept works by correcting and maintaining positional faults that develop due to injury or repetitive strain on the tendons and joint. When these correctional mobilizations are applied to the joint, function is restored without pain and repeated mobilization provide long lasting results. ${ }^{9}$ It also maintains and aligns structural tissue length tension association for longer periods. Taping not only 


\begin{tabular}{|c|c|c|c|c|c|c|c|c|}
\hline \multicolumn{9}{|c|}{ Table II: Mutlivariate analysis of variance } \\
\hline \multirow[t]{2}{*}{ Variable \& group } & \multirow[t]{2}{*}{ Pre-test } & \multirow[t]{2}{*}{ Post-test } & \multirow[t]{2}{*}{ Follow-up } & \multicolumn{3}{|c|}{ Within Group Change } & \multicolumn{2}{|c|}{$\begin{array}{c}\text { Group } \times \mathrm{T} \\
\text { Interaction }\end{array}$} \\
\hline & & & & $t$ & $\mathbf{P}$ & $\mathrm{MD}(95 \% \mathrm{Cl})$ & $F$ & $\mathbf{P}$ \\
\hline \multicolumn{9}{|l|}{ Grip Strength } \\
\hline Group A & $32.7 \pm 1.41$ & $42.1 \pm 1.30$ & $53.5 \pm 2.13$ & 10.25 & $.00^{\mathrm{a}}$ & $7.97(6.38-9.56)$ & 2.23 & $0.02^{\mathrm{a}}$ \\
\hline Group B & $33.3 \pm 1.34$ & $38.6 \pm 2.82$ & $42.3 \pm 1.97$ & 5.74 & $.00^{\mathrm{a}}$ & $5.57(3.59-7.55)$ & & \\
\hline \multicolumn{9}{|c|}{ Patient Rated Tennis } \\
\hline \multicolumn{9}{|l|}{ Elbow Evaluation } \\
\hline Group A & $78.06 \pm 2.76$ & $60.61 \pm 3.78$ & $26.86 \pm 2.43$ & 8.04 & $.00^{\mathrm{a}}$ & $14.55(18.24-10.85)$ & 5.28 & $0.006^{\mathrm{a}}$ \\
\hline Group B & $76.93 \pm 1.71$ & $38.06 \pm 5.73$ & $7.66 \pm 1.63$ & 12.42 & $.00^{\mathrm{a}}$ & $18.7(21.79-15.63)$ & & \\
\hline
\end{tabular}

approximates skin elasticity but also stretches it to $140 \%$ of its resting length. ${ }^{10-11}$ This is why Mulligan MWM is known to be effective for not just reducing pain but improving functional performances also. Previous evidences also concluded that Mulligan and Cyriax improves functional status of patients but these were done individually. ${ }^{12-13}$ Amro et al. conducted a research to study the effectiveness of Mulligan and conventional treatment in which they applied MWM and taping and assessed pain and grip strength along with Patient rated tennis elbow evaluation. They concluded same resulted as were deducted by our study. The research was also based on a treatment of 4 weeks. ${ }^{14} \mathrm{Another}$ study was conducted to compare the effectiveness of Cyriax and supervised exercise program for tennis elbow. This study was based on 20 patients and they were assessed for pain and functional status by using VAS and Tennis Elbow Function Scale. The researchers concluded that both interventions were significantly effective in improving pain and functional status of patients ${ }^{15}$. This study had the same treatment duration like the one discussed earlier i.e. 4 weeks. Results of current study concluded that Cyriax group patients improved more in terms of grip strength as compared to those who were provided Mulligan MWM mobilization i.e. $p \leq 0.05$. Tipton et al. recommended that it not only increases and maintains forces that are applied on tendons, bones and ligaments but it also increases functional ability and strength of these structures. ${ }^{16}$ Dynamometer was used for wrist extension and grip strength and Visual Analogue Scale was used to assess pain. Significant changes were reported to be found in extension and grip strength i.e. $p=$ 0.001 . Thus taping was concluded to have impressive effect in individuals with lateral epicondylitis. ${ }^{17}$

The current study also showed improvement in pain, grip strength and functional status of patients. The results were found to be applicable to the population visiting the hospital and gender differences were also not evaluated as males and females always are known to have different levels of physical activity because of changes in strength. Thus results may vary for both

\section{Conclusion}

The present study concluded that Grip strength was improved by Cyriax manual therapy better than mulligan technique, while Functional status was improved by Mulligan techniques better than Cyriax manual therapy.

\section{References}

1. Bhabra G, Wang A, Ebert JR, Edwards P, Zheng M, Zheng MH. Lateral elbow tendinopathy: development of a pathophysiology-based treatment algorithm. Orthop. J. Sports Med. 2016 Nov 1;4(11):2325967116670635.

2. Kushner S, Reid DC. Manipulation in the treatment of tennis elbow. J Orthop Sports Phys Ther. 2016 Mar;7(5):264-72.

3. Coombes BK, Bisset L, Vicenzino B. Management of lateral elbow tendinopathy: one size does not fit all. J Orthop Sports Phys Ther . 2015 Nov;45(11):938-49.

4. Arirachakaran $A$, Sukthuayat $A$, Sisayanarane $T$, Laoratanavoraphong S, Kanchanatawan W, Kongtharvonskul J. Platelet-rich plasma versus autologous blood versus steroid injection in lateral epicondylitis: systematic review and network meta-analysis. Journal of Orthopaedics and Traumatology. 2016 Jun 1; 17(2):10112.

5. Sanders Jr TL, Maradit Kremers H, Bryan AJ, Ransom JE, Smith J, Morrey BF. The epidemiology and health care burden of tennis elbow: a population-based study. The American journal of sports medicine. 2015 May; 43(5):1066-71.

6. Stasinopoulos D, Stasinopoulos I. Comparison of effects of eccentric training, eccentric-concentric training, and eccentric-concentric training combined with isometric contraction in the treatment of lateral elbow tendinopathy. Journal of Hand Therapy. 2017 Jan 1; 30(1):13-9.

7. Dimitrios S. Lateral elbow tendinopathy: Evidence of physiotherapy management. World journal of orthopedics. 2016 Aug 18;7(8):463.

8. Viswas R, Ramachandran R, Korde Anantkumar P. Comparison of effectiveness of supervised exercise program and Cyriax physiotherapy in patients with tennis 
elbow (lateral epicondylitis): a randomized clinical trial. The scientific world journal. 2012; 2012.

9. Nagrale AV, Herd CR, Ganvir S, Ramteke G. Cyriax physiotherapy versus phonophoresis with supervised exercise in subjects with lateral epicondylalgia: a randomized clinical trial. Journal of Manual \& Manipulative Therapy. 2009 Jul 1;17(3):171-8.

10. MacDermid JC. The Patient-Rated Tennis Elbow Evaluation (PRTEE)@ User Manual. 200722

11. Anakwe RE, Huntley JS, McEachan JE. Grip strength and forearm circumference in a healthy population. J Hand Surg Eur. 2007; 32(2):203-9.

12. Walker JM. Deep transverse frictions in ligament healing. J Orthop Sports PhysTher. 1984;6(2):89-94.24.

13. Goats GC. Massage--the scientific basis of an ancient art: Part 2. Physiological and therapeutic effects. $\mathrm{Br} \mathrm{J}$ Sports Med. 1994; 28(3):153-6.25.
14. Amro A, Diener I, Bdair WO, Isra'M H, Shalabi Al, Dua'l I. The effects of Mulligan mobilisation with movement and taping techniques on pain, grip strength, and function in patients with lateral epicondylitis. Hong Kong Phys J. 2010; 28(1):19-23.33.

15. Herd CR, Meserve BB. A systematic review of the effectiveness of manipulative therapy in treating lateral epicondylalgia. J Man ManipTher. 2008; 16(4):225237.26.

16. Tipton, C M, Vailes, A C and Matthes, R D. 'Experimental studies on the influences of physical activity on ligaments, tendons and joints: A brief review'. 1987; Act MediScandi, 711, 157-168

17. Shamsoddini A, Hollisaz MT, Hafezi R. Initial effect of taping technique on wrist extension and grip strength and pain of Individuals with lateral epicondylitis. Iran Rehabili J. 2010; 8(1):24-8.

\section{Copyright Policy}

All Articles are made available under a Creative Commons "Attribution-NonCommercial 4.0 International" license. (https://creativecommons.org/licenses/by-nc/4.0/). Copyrights on any open access article published by Journal Riphah college of Rehabilitation Science (JRCRS) are retained by the author(s). Authors retain the rights of free downloading/unlimited e-print of full text and sharing/disseminating the article without any restriction, by any means; provided the article is correctly cited. JRCRS does not allow commercial use of the articles published. All articles published represent the view of the authors and do not reflect the official policy of IRCRC 